\title{
Effectiveness of mobile apps in teaching field-based identification skills
}

Article

Accepted Version

Thomas, R. L. and Fellowes, M. D. E. (2017) Effectiveness of mobile apps in teaching field-based identification skills. Journal of Biological Education, 51 (2). pp. 136-143. ISSN 0021-9266 doi:

https://doi.org/10.1080/00219266.2016.1177573 Available at https://centaur.reading.ac.uk/62773/

It is advisable to refer to the publisher's version if you intend to cite from the work. See Guidance on citing.

To link to this article DOI: http://dx.doi.org/10.1080/00219266.2016.1177573

Publisher: Taylor \& Francis

All outputs in CentAUR are protected by Intellectual Property Rights law, including copyright law. Copyright and IPR is retained by the creators or other copyright holders. Terms and conditions for use of this material are defined in the End User Agreement.

\section{www.reading.ac.uk/centaur}

\section{CentAUR}

Central Archive at the University of Reading 
Reading's research outputs online 
2 Effectiveness of mobile apps in teaching field-based

3 identification skills

4

$5 \quad$ Rebecca L. Thomas* \& Mark D. E. Fellowes

6

$7 \quad$ * Corresponding author

8 People and Wildlife Research Group, School of Biological Sciences, Harborne Building,

9 University of Reading, Whiteknights, Reading, Berkshire, RG6 6AS, UK

10 Email addresses: rebecca.thomas@reading.ac.uk; m.fellowes@ reading.ac.uk

11 Tel.: +44(0) 1183788167

12

13

14

15

16

17

18

19

20

21

22

23 


\section{Abstract}

25

It has been suggested that few students graduate with the skills required for many ecological careers, as field-based learning is said to be in decline in academic institutions. Here, we asked if mobile technology could improve field-based learning, using ability to identify birds as the study metric. We divided a class of ninety-one undergraduate students into two groups for field-based sessions where they were taught bird identification skills. The first group has access to a traditional identification book and the second group were provided with an identification app. We found no difference between the groups in the ability of students to identify birds after three field sessions. Furthermore, we found that students using the traditional book were significantly more likely to identify novel species. Therefore, we find no evidence that mobile technology improved students' ability to retain what they experienced in the field; indeed, there is evidence that traditional field guides were more useful to students as they attempted to identify new species. Nevertheless, students felt positively about using their own smartphone devices for learning, highlighting that while apps did not lead to an improvement in bird identification ability, they gave greater accessibility to relevant information outside allocated teaching times.

\section{Keywords}

Field-based teaching; identification skills; mobile apps; technology in teaching; teaching/learning strategies; smartphone devices 
54

Teaching in the environmental biosciences (e.g. botany, ecology, environmental biology, zoology) focuses on supporting students as they gain an appreciation of the diversity of life, how species interact with their environments and how we as a species affect their abundance and distribution. The ability to identify taxa to appropriate levels and to study these organisms in the field is therefore a key skill for field biologists (IEEM 2011a; IEEM 2011b). In spite of the importance of field skills to these subjects, it has been suggested that the provision of field teaching is in decline (Scott et al. 2014; Smith 2004) as we see a generational attrition in academic staff with the required knowledge of field natural history to appropriately teach such courses. For example, taxonomy is under-represented in many undergraduate bioscience degree programmes (Leather and Quicke 2009), which will have a negative effect on global conservation efforts, as protecting species starts with putting the correct name to it (Hopkins and Freckleton 2002). This also has important implications for graduate employment, as many employers in the ecological sector are looking for graduates with these skills (IEEM 2011a; IEEM 2011b). However, Maw et al. (2011) argue that higher education programmes contain reasonable levels of field work and that this practice is not in decline. They demonstrated that this field work took place in the UK as well as part of overseas field courses, which are considered important for student recruitment. Either way, field work remains an important aspect of many higher degree programmes, especially in the natural sciences, and also in secondary and primary education (Tilling 2004, Boyle et al. 2007, Hope 2009).

The benefits of field experience in education as an important mode of active learning have been demonstrated (Boyle et al. 2007; Easton and Gilburn 2011; Goodenough et al. 2014), and are crucial in placing the subject in its real-world context. Field work can be of benefit to a wide diversity of students (Fuller et al. 2006) and it provides a novel learning environment away from traditional classroom teaching (Falk et al. 1978). There is a strong tradition of field work in the biosciences as a way to develop practical skills (Goulder et al. 2012), as well as increasing higher order learning (Rickinson et al. 2004) and student confidence (Boyle et al. 2007). For example, Hamilton-Ekeke (2007) found that students learnt more about biodiversity and ecology by undertaking a field trip than students taught in the classroom.

The ability to correctly identify species is the basis of field biology; field work can be used to actively engage and encourage students to identify the species they encounter (Scott et al. 2012). Birds are a tractable group for students to work with because most students start with some familiarity with the group, their relative visibility and the comparative ease at which identification can be taught, when compared with groups such as invertebrates or plants. In the UK, there are only around 250 regularly encountered species, bird identification guides are easy to use and the bird does not need to be caught to be identified. While birds therefore provide a useful entry group to enable students to gain key field 
skills, it remains the case that finding effective methods to teach large groups in the field can be challenging, and so it is important to consider a variety of teaching methods. Previous research found that hands on teaching of bird identification skills using stuffed specimens led to better grades in subsequent testing (Randler and Bogner 2006), although previous studies found no difference when compared with a teacher centred slide presentation (Randler and Bogner 2002). To date, research using field work based teaching of identification skills is lacking.

Tablet devices and mobile apps are increasingly being used in education to enhance learning opportunities (Morris et al. 2012) and they are increasingly being used in the field (Welsh and France 2012). Many students now own their own personal smartphone or tablet device (Welsh and France 2012), and these are now often used formally or informally in classes for learning (Woodcock et al. 2012). This presents an opportunity to engage students in their learning while improving digital literacy. They also present a novel learning tool, which could be used to improve field teaching of species identification skills although whether they are a more effective learning tool compared with more traditional methods remains unknown.

Here, we ask if the ability of students to identify bird species following three one-hour field sessions was affected by the tools used to support teaching, in this case a traditional field guide and a comparable mobile app. Furthermore, we asked if the use of mobile technology increased student engagement with bird identification.

\section{Method}

\section{Participants}

Ninety-one undergraduate students from the University of Reading, UK, participated in the study (63 females; 28 males) in January-March 2013. All participants were enrolled in an introductory Part One Ecology module and represented a variety of undergraduate disciplines, although most students were undertaking BSc Zoology. It was explained to the students that participation was not compulsory, and consent forms were completed by the students after the study had been explained (all students consented to take part). The project was subject to ethical review, according to the procedures specified by the University of Reading Ethics Committee and was formally approved.

\section{Procedure}

During the module, the students were divided into two groups (A and B) for practical lessons, with each group getting three two-hour field-based sessions over a period of six weeks. Within the groups A and B the students were divided into two further groups (A1, A2; B1, B2) with students in group 1 $(\mathrm{n}=51)$ being allocated a traditional bird identification guide (Pocket Guide to British Birds, RSPB) and students in group $2(\mathrm{n}=40)$ being asked to download a bird identification app (Birds of Britain, 
121 CleverMatrix Ltd) onto their own personal smartphone or tablet device. Twenty nine percent of the

122 students did not own their own personal smartphone and these students were automatically allocated

123 into group 1 , and of the $71 \%$ who did own their own device 40 students were randomly allocated into

124 group 2 and the remainder were allocated to group 1.

125 In the field-based sessions the groups were further divided into four smaller groups where they were 126 allocated a demonstrator (to help them with bird identification) and each student spent one hour in the 127 field identifying the birds they came across, working in pairs or groups of three. The demonstrator 128 was allowed to aid in identification, but they were instructed to not give the answer straight away to 129 the student, but to instead encourage them to identify the species themselves using the book or app as 130 appropriate. The students were also asked to record weather conditions, each species encountered and 131 an estimate of the number seen, as well as any records of interesting behaviour (e.g. feeding, singing). 132 Following completion of the hour in the field, the students returned indoors, where any unidentified bird species were discussed with the demonstrators.

Bird identification skills

To get a baseline of existing knowledge of each student's ability to identify common UK bird species all students were asked to complete an initial spots test (hereafter known as spots test one). The spots test was undertaken under exam conditions and consisted of individual PowerPoint slides showing photographs of 30 species commonly found on the University campus. Each slide was shown for one minute and each student independently wrote down the species common name if it was known to them (they were not able to use an identification aid to help them). These were collected and each student was given two marks out of a possible 30. The first mark was given if the student had given an inaccurate but almost complete answer (e.g. if the student had written the word gull for the Blackheaded gull; hereafter known as the generous mark), the second mark was given if the student knew the complete common name of the species (hereafter known as the harder mark). It was important to distinguish the two marks as the first tests for a general knowledge of the species and the second tests that the student had fully and correctly identified the species. The marking was completed by the same individual to reduce bias. Neither mark contributed towards their overall module grade.

Following completion of the three field-based sessions, the students were asked to complete a second spots test (hereafter known as spots test two). This test followed the same format as spots test one, although different species and/or photographs were used, and the students were not able to use any aids as before. The students were again given two sets of marks (generous and harder marks) for each of the 30 species, the marking was completed by the same individual as before and the marks did not contribute towards their overall module grade. A third spots test (hereafter known as the video spots test) was used to test the students' ability to identify bird species that they would likely not have encountered before and was carried out following spots test two. In this test, six videos were shown 
twice for one minute. The students were told that they were allowed to use their identification aid (either the book or smartphone app, depending on their group) to help them identify the species.

\section{Questionnaires}

Each student was asked to complete a questionnaire before the experiment began (hereafter known as questionnaire one). The questions were designed to ask the students about ownership and use of smartphone devices; their opinions about using smartphone technology in teaching; how the student judged their interest in field biology and wild birds; and how the student rated their bird identification skills. A second questionnaire was used following completion of the three field-based sessions, one version for the students who had used the traditional bird identification guide and another for the students who has used the smartphone app (hereafter known as questionnaire $2 \mathrm{a}$ and $2 \mathrm{~b}$ respectively). Each questionnaire used a 5 point Likert Scale and was subject to ethical review, according to the procedures specified by the University of Reading Ethics Committee, and was formally approved.

\section{Data analysis}

In all cases data were tested for normality and where appropriate parametric tests were performed. All analyses were carried out using Minitab (Minitab 17 Statistical Software 2010). To compare the differences in bird identification knowledge in all students, between the pre and post field-based sessions, paired t-tests were used. To compare the differences in learning between the app and book groups, two-sample t-tests were used. Mann-Whitney tests were used to compare the change of opinions in the questionnaires (Questionnaire 1 and 2a or 2b) between the pre and post field-based sessions and between the app and book groups.

\section{Results}

\section{Bird identification skills}

There was a significant improvement in total number of birds identified between spots tests one (ST1) and two $(\mathrm{ST} 2)$ for the harsher mark $\left(\mathrm{t}_{90}=13.73, \mathrm{p}<0.001\right.$, mean ST1 = 9.7, mean ST2 = 15.6; Figure 1) and the generous mark $\left(\mathrm{t}_{90}=12.44, \mathrm{p}<0.001\right.$, mean $\mathrm{ST} 1=15.6$, mean ST2 = 20.7; Figure 1). No significant differences were found between the groups of students using the app or book measured with the harsher mark $\left(\mathrm{t}_{88}=1.18, \mathrm{p}=0.24\right)$ or the generous mark $\left(\mathrm{t}_{86}=1.41, \mathrm{p}=0.16\right)$. In the video spots test, there was no significant difference in the ability of students to identify unfamiliar birds between the app or book groups $\left(\mathrm{t}_{80}=1.68, \mathrm{p}=0.1\right)$, although when students who had correctly identified over 20 species in spots test one with the hasher mark were removed $(n=9)$, the students from the book group were able to identify significantly more birds than students with the app $\left(\mathrm{t}_{74}=\right.$ $2.02, \mathrm{p}=0.047$, mean app $=2.49$, mean book $=3.11$; Figure 2).

\section{Questionnaires}


Ninety one percent of students considered themselves to be interested in field biology, $70 \%$ were interested in wild birds and $23 \%$ of students watched birds on a daily or weekly basis. Only $12.5 \%$ of students rated their ability to identify UK bird species as good or excellent. Seventy one percent of students owned a smartphone, with only $14 \%$ having used it formally and $65 \%$ having used it informally in classes. In week one $70 \%$ of students thought that using a smartphone in teaching and learning was a good idea, and there was no significant change of opinion between week one and seven between the students in the book and app groups $\left(\mathrm{w}_{40,51}=1962.5, \mathrm{p}=0.290\right)$. Seventy four percent of students would be happy to use their own smartphone for fieldwork when asked in week one and there was no significant change of opinion between week one and seven between the students in the book and app groups $\left(\mathrm{w}_{40,40}=1659.5, \mathrm{p}=0.677\right)$.

\section{Discussion}

Over the course of the three field-based sessions the students' ability to identify common bird species increased significantly, although no differences were found between the students who has been using the bird identification book or those using the mobile app downloaded to their smartphone device. Before the field-based sessions, students on average were able to identify ten species of common UK birds (out of a possible 30) and at the end this has increased to 16 species. When asked to identify previously unknown bird species, using a video spots test (and having removed those students who already had good bird identification skills) and either the bird identification book or the mobile app, students were more likely to correctly identify the species with the field guide. This is likely due to the relative ease of skimming through the book rather than searching through the smartphone app.

While nearly all of the students (91\%) considered themselves to be interested in field biology and many (70\%) considered themselves to be interested in wild birds, this did not translate into an active interest for many. When they were asked whether they watched birds on a daily or weekly basis, only $23 \%$ of students actually actively watched birds on a regular basis. This figure matches well with our findings of the actual ability of the students to identify common UK bird species (using the spots tests) and unless rectified would contribute to the lack of identification skills among UK graduates of relevant disciplines (Leather and Quicke 2009; IEEM 2011a; IEEM 2011b).

Graduate employability is an important element of many higher education league tables and something which universities will constantly strive to improve. It has been suggested that few graduates have the identification skills to be employable in the ecological sector without further training (Warren 2015), and although this has been disputed, it is acknowledged that there is still an important skills gap. Using smartphone devices with identification apps could be a useful way of engaging students outside of formal teaching opportunities, as many students here reported that they had begun using their apps more regularly outside of classes, whereas none of the students with the identification books reported using them outside of the standard teaching time. This is likely due to 
the accessibility of the students' smartphone devices and that they were unlikely to carry their identification book with them. One student commented 'I feel that the app was very helpful in identifying birds, mainly for the fact that I would always have my phone with me so it was convenient when I found a bird I didn't recognise to look it up'. Other students still had a preference for the book arguing that it was more challenging which helped them to learn more, 'I was part of the book group and find this also helped my score to increase. This is because you have to really look and remember specific details on the birds in order to identify them in the book. It takes longer and is harder I feel than the app'.

It is important to note that allocation of students to smartphone user/non-smartphone user was not random, for two reasons. First, logistically, it would have been exceptionally difficult to purchase sufficient smartphones for a highly replicated, randomised trial. Second, and more important, every student will be familiar with using books, while not every student will be familiar with using a given smartphone/operating system. Here, we assume that students who own smartphones are proficient at using them, and also at using smartphone apps. If we allocated non-smartphone using students to the smartphone using group, then we would expect that we would in essence be testing the difference in ability to develop a competency in using the device and app, rather than the ability to use an app or book to identify birds. Given the near ubiquity of smartphones among the 16-24 age group (currently $90 \%$ in the UK; Ofcom 2015), the relative educational similarities of the cohort tested and the outcome of the initial test, we see no strong reason to assume $a$ priori differences between our experimental groups.

A large number of our students owned their own smartphone devices (71\%); these figures are similar to those found by Welsh and France (2012), where in 2012 they found that $70 \%$ of their students owned smartphones. They suggest that educators should encourage smartphone use in the field to aid students learning (Welsh and France 2012). Although very few of our students have used their smartphones formally in their teaching (14\%), many more have used it informally (65\%) to access information during lectures for example and they feel positively about using their own devices in class (70\%) and in field classes (74\%). Increasing smartphone use in teaching has many benefits when used alongside face-to-face teaching, such as improving digital literacy skills (Woodcock et al. 2012), but it also comes with its own challenges as not all students own their own device. Here we used a 'bring your own device' policy, but if apps were to be used more formally and consistently in our teaching we would need to make devices available for those students who do not own them. This could present a challenge for some higher education institutions, but this will undoubtedly change over time.

\section{Conclusions}

The growth of mobile, smart devices has resulted in the suggestion that this may provide a new opportunity to engage students in active learning. However, we found no differences between student 
groups tasked with improving their bird identification skills between those using traditional (field guide) and new (mobile app) approaches. Indeed, once we excluded individuals who started the class already possessing strong bird identification skills (nine individuals), those who used the field guide were more likely to correctly identify novel species, suggesting that in this situation at least, traditional technology provides a superior support to learning. Nevertheless, mobile devices offered more opportunities for students to engage with the subject outside of the allocated teaching time, due to their general portability and accessibility. Field-based learning is an important method for teaching environmental bioscience students species identification skills, and utilising mobile smartphone devices and apps is a novel approach to doing this. Here, students were both happy to use their own devices and more generally were supportive of using their own smartphone devices in their learning. Smartphones and other mobile devices offer a positive way to enhance field-based learning, with the ever increasing development of apps for species identification and recording, note-taking, geotagging, as well as others to enhance teaching and learning in the field.

\section{References}

Boyle, A., S. Maguire, A. Martin, C. Milsom, R. Nash, S. Rawlinson, A. Turner, S. Wurthmann and S. Conchie. 2007. "Fieldwork is Good: the Student Perception and the Affective Domain. "Journal of Geography in Higher Education 31 (2): 299-317.

Easton, E. and A. Gilburn. 2011. "The field course effect: gains in cognitive learning in undergraduate biology students following a field course." Journal of Biological Education 46 (1): 29-35.

Falk, J. H., W. W. Martin and J. D. Balling. 1978. "The novel field-trip phenomenon: Adjustment to novel settings interferes with task learning." Journal of Research in Science Teaching 15 (2): 127-134.

Fuller, I. A. N., S. Edmondson, D. France, D. Higgitt and I. Ratinen. 2006. "International Perspectives on the Effectiveness of Geography Fieldwork for Learning." Journal of Geography in Higher Education 30 (1): 89-101.

Goodenough, A. E., R. N. Rolfe, L. MacTavish and A. G. Hart. 2014. "The Role of Overseas Field Courses in Student Learning in the Biosciences." Bioscience Education DOI: 10.11120/beej.2014.00021.

Goulder, R., G. W. Scott and L. J. Scott. 2012. "Students' Perception of Biology Fieldwork: The example of students undertaking a preliminary year at a UK university." International Journal of Science Education 35 (8): 1385-1406.

Hamilton-Ekeke, J. T. 2007. "Relative Effectiveness of Expository and Field Trip Methods of Teaching on Students' Achievement in Ecology." International Journal of Science Education 29 (15): 1869-1889.

Hope, M. 2009. "The Importance of Direct Experience: A Philosophical Defence of Fieldwork in Human Geography." Journal of Geography in Higher Education 33 (2): 169-182. 
Hopkins, G. W. and R. P. Freckleton. 2002. "Declines in the numbers of amateur and professional

IEEM. 2011a. "Ecological skills, shaping the profession for the 21st century". Institute of Ecology and Environmental Management.

IEEM. 2011b. "Closing the gap: rebuilding ecological skills in the $21^{\text {st }}$ century. " Institute of Ecology and Environmental Management.

Leather, S. R. and D. J. L. Quicke. 2009. "Where would Darwin have been without taxonomy?" Journal of Biological Education 43 (2): 51-52.

Maw, S. J., A. L. Mauchline and J. R. Park. 2011. "Biological Fieldwork Provision in Higher Education." Bioscience Education 17: DOI: 10.3108/beej.17.1.

Minitab 17 Statistical Software. 2010. [Computer software]. State College, PA: Minitab, Inc. (www.minitab.com).

Morris, N. P., L. Ramsay and V. Chauhan. 2012. "Can a tablet device alter undergraduate science students' study behavior and use of technology? " 36 (2):97-107.

Ofcom. 2015. "The Communications Market Report." Available at: http://stakeholders.ofcom.org.uk/binaries/research/cmr/cmr15/CMR_UK_2015.pdf

Randler, C. and Bogner, F.X. 2002. "Comparing methods of instruction using bird species identification skills as indicators." 36 (4): 181-188.

Randler, C. and Bogner, F.X. 2006. "Cognitive achievements in identification skills." 40 (4):161-165.

Rickinson, M., J. Dillon, K. Teamey, M. Morris, M. Y. Choi, D. Sanders and P. Benefield. 2004. "A review of research on outdoor learning". NfER. Field Studies Council Occasional Publication 87.

Scott, G. W., M. Boyd, L. Scott and D. Colquhoun. 2014. "Barriers To Biological Fieldwork: What Really Prevents Teaching Out of Doors?" Journal of Biological Education 49 (2): 165-178.

Scott, G. W., R. Goulder, P. Wheeler, L. J. Scott, M. L. Tobin and S. Marsham. 2012. "The Value of Fieldwork in Life and Environmental Sciences in the Context of Higher Education: A Case Study in Learning About Biodiversity." Journal of Science Education and Technology 21 (1): 11-21.

Smith, D. 2004. "Issues and trends in higher education biology fieldwork." Journal of Biological Education 39 (1): 6-10.

Tilling, S. 2004. "Fieldwork in UK secondary schools: influences and provision." Journal of Biological Education 38(2): 54-58.

Warren, J. 2015. "Save field biology skills from extinction risk"

https://www.timeshighereducation.co.uk/comment/opinion/save-field-biology-skills-from-extinctionrisk/2018721.article

Welsh, K. and D. France. 2012. "Smartphones and fieldwork." Geography 97: 47-51.

Woodcock, B., A, Middleton and A. Nortcliffe. 2012. "Considering the Smartphone Learner: an investigation into student interest in the use of personal technology to enhance their learning. " Student Engagement and Experience Journal, 1(1). 


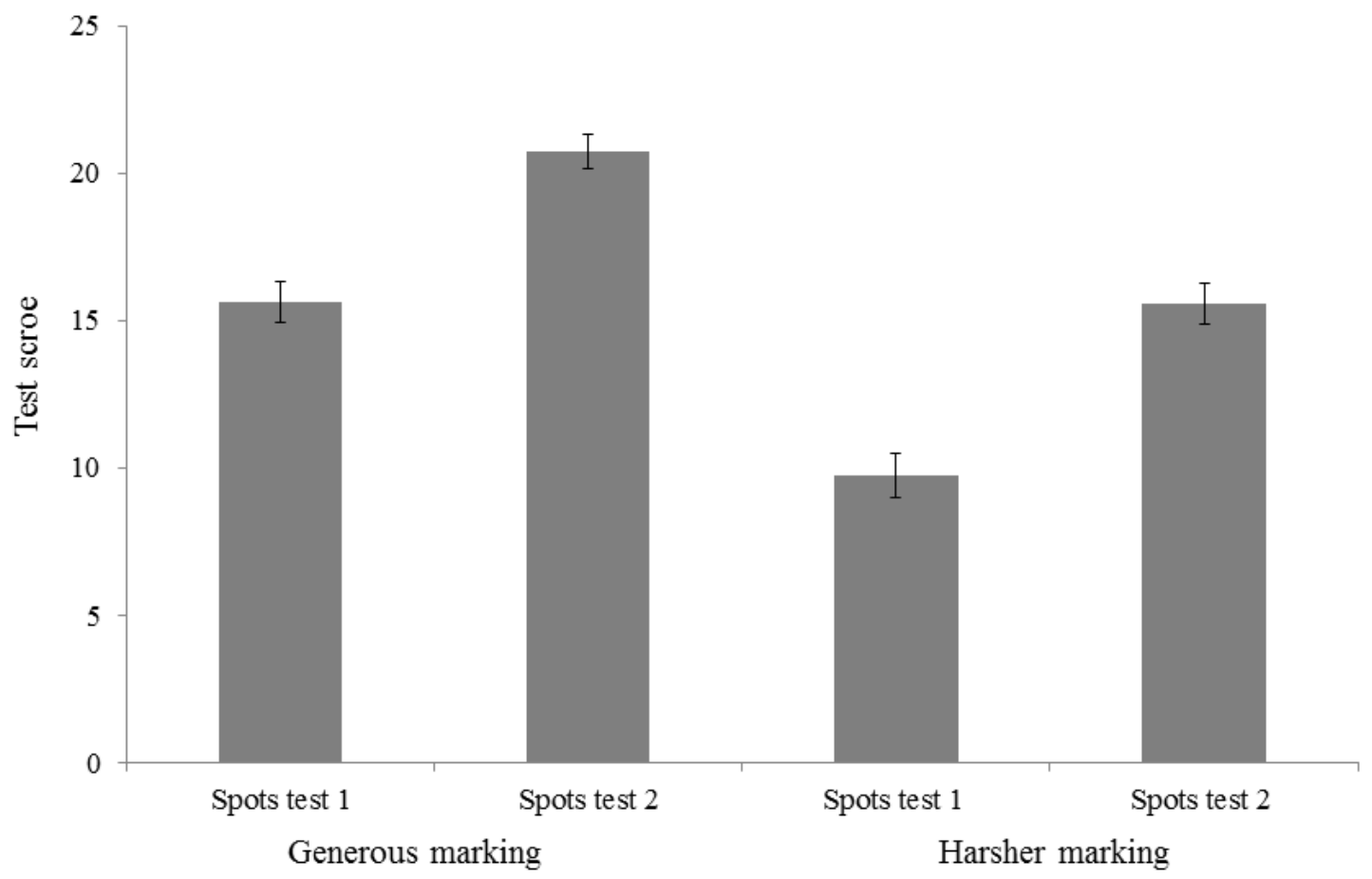

358

359

Figure 1: Mean number of birds identified (out of a possible 30) in the first and second spots test in the generous and harsher marking for all of the students $( \pm$ S.E.).

361

362

363

364

365

366

367

368

369

370

371

372

373

374

375

376

377 


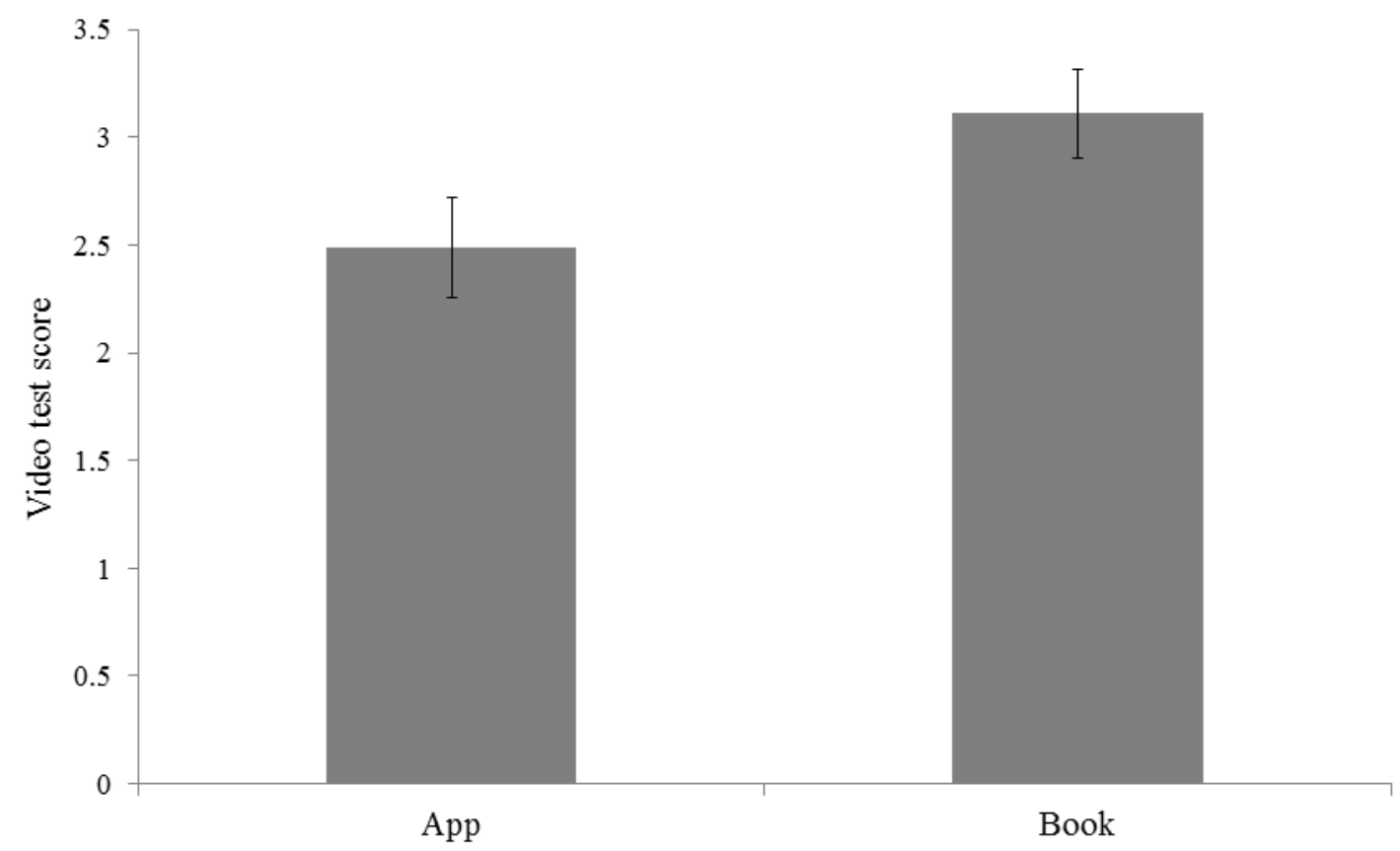

378

379 Figure 2: Mean number of correctly identified (out of a possible 6) 'un-encountered' birds

380 during the video spots test, when the students with good bird identification skills $(\mathrm{n}=9)$ were 381 removed from the analysis $( \pm$ S.E.). 